\title{
HYDROGEN EMBRITTLEMENT AND PECULIAR PRORERTIES OF DETERMINING THE CONCENTRATION OF HYDROGEN IN STRUCTURAL STEELS
}

\author{
1'Julia AVERINA, 'Dmitry ZHUKOV, 'Victoria TSEVKOVA, "Irina SAFAROVA, "Elena SUBCHEVA \\ ${ }^{1}$ Russian University of Chemical Technology Mendeleev, Moscow, Russia, averinajm@mail.ru \\ 2JSC NPO Energomash named after Academician V.P. Glushko, Moscow, Russia
}

https://doi.org/10.37904/metal.2020.3494

\begin{abstract}
Alloys used for the manufacture of various structures must be strong and easy to process. Under certain conditions, hydrogen can adversely affect the fracture characteristics of most structural alloys. A classic example is hydrogen embrittlement of high-strength martensitic steel, which is the result of a high concentration of hydrogen in the metal. An extremely high internal concentration of hydrogen in such alloys can be created during chemical or electrochemical processing, such as etching, electroplating, and removing coatings used in the production of a particular product. Over time, this hydrogen forms bubbles and cracks on the internal surfaces of grain boundaries or inclusions and causes slow destruction. This type of embrittlement, caused by hydrogen located in the internal volumes of the alloy and developing during the stay of the alloy under external load, is called internal hydrogen embrittlement. This embrittlement is typical for a large number of alloys used in mechanical engineering. The article discusses the features of the origin of hydrogen and the form of its existence in structural alloys. The process of hydrogen embrittlement in alloyed structural steels is studied. The method of performing analysis on the "G8 GALILEO" hydrogen analyzer for structural alloys is adapted and described. The corresponding results of the work and recommendations are given.
\end{abstract}

Keywords: Hydrogen embrittlement, carrier gas, chemical composition of the alloy, hydrogen analyzer

\section{INTRODUCTION}

Predicting the durability of a structure currently made of virtually any alloy, one must take into account the degree of harmful effect that hydrogen exerts on the properties of the alloy when it is aged in any hydrogencontaining medium at the stages of preparation of this alloy, its processing and operation. Hydrogen embrittlement is a complex process, and its reliable prediction is very difficult or even impossible. Therefore, in a broad sense, hydrogen embrittlement is a serious cause causing premature destruction of mechanical structures; either general corrosion is an even more serious cause of such destruction.

The complexity of the hydrogen embrittlement process may result from the collective action of many factors that affect both the degree and type of embrittlement. Most of them are interdependent, which makes it difficult to understand and predict the process. The deterioration of mechanical properties is not only the result of hydrogen-metal interaction, for example. This deterioration may be due to the action of any other or several mechanisms of embrittlement. The true mechanism that is directly responsible for embrittlement is determined by the rate of hydrogen transfer, the amount and distribution of hydrogen capable of participating in the reaction both in the regions of its formation and in the places of interaction $[1,2]$.

\section{HIGH TEMPERATURE HYDROGEN EMBRITTLEMENT}

The transfer rate and placement of hydrogen depend on other factors: the chemical composition of the alloy, including residual impurities, microstructures, stress state, temperature, etc. [3]. 
At temperatures above $200{ }^{\circ} \mathrm{C}$, hydrogen moves relatively easily in the body-centred cubic structure of the iron lattice, and those forms of hydrogen embrittlement that are inherent in martensitic, ferritic, and austenitic steels at temperatures close to room temperature are usually not observed at elevated temperatures. Hydrogen damage at elevated temperatures is associated with the formation of reaction products between hydrogen and some chemically active substances in the alloy volume [3-5]. In steels, the most noticeable reaction is the formation of methane between hydrogen and carbon.

$\mathrm{Fe}_{3} \mathrm{C}+2 \mathrm{H}_{2}=3 \mathrm{Fe}+\mathrm{CH}_{4}($ gas $)$

In this case, steel damage is a combined result of the formation of internal cracks filled with gaseous methane, often under very high pressure, and decarburization of the matrix lattice, this type of hydrogen embrittlement is hydrogen corrosion. It can occur in all steels if they contain carbon in a form accessible for the reaction and are sufficiently mobile to react with hydrogen and form methane along grain boundaries or other weakened interface in the internal volumes of steel $[1,4,6]$.

It is obvious that any factor causing a change in the thermodynamic stability of carbon, its transfer rate or the strength of the interface and the distribution of the corresponding elements of the microstructure will affect the resistance of steel to hydrogen corrosion. The susceptibility of steel to hydrogen corrosion can change under the influence of alloying elements that affect the activity of carbon, with varying hydrogen pressure and temperature, changing grain size, composition of their boundaries, degree of hardening and other microstructural parameters [3,7].

The main method used today to overcome hydrogen corrosion is alloy age. The introduction of carbide-forming elements such as chromium, molybdenum, tungsten, tantalum and vanadium, significantly increases the resistance of steel against this type of damage. Silicon, nickel and copper have very little effect on the susceptibility of steel to hydrogen corrosion. These elements do not form stable carbides and therefore do not significantly affect the carbon activity, but simply dissolve in the ferrite lattice. Manganese is slightly more effective, because it forms the compound $\mathrm{Mn}_{3} \mathrm{C}$. Chrome, tungsten and molybdenum are very effective in suppressing hydrogen corrosion, since they form stable carbides. Titanium, vanadium, zirconium and niobium, as well as tantalum and thorium form highly stable carbides and actively eliminate hydrogen corrosion [1, 4, 8].

To eliminate hydrogenation of metals and reduce their strength characteristics, it is necessary to have data on the composition of hydrogen in structural alloy steels.

A hydrogen content of only 4 ppm (parts per million) - something that can dissolve in steel - can cause:

- $\quad$ thin hairy cracks;

- $\quad$ hydrogen fragility;

- $\quad$ hydrogen bubbles;

- $\quad$ loss of tensile plasticity.

The task was to determine the concentration of hydrogen in the alloyed structural steels of the grades EK49 (03X10H8K4MF) and EK94 (03X9N9K5M3). The chemical composition of these heats is shown in Table 1 and 2.

Table 1 The chemical composition of steel grade EK49 (wt\%)

\begin{tabular}{|c|c|c|c|c|c|c|c|}
\hline Fe & Ni & Cr & Co & V & Mn & Mo & C \\
\hline Main & 7.94 & 9.23 & 4.54 & 0.13 & 0.10 & 0.10 & 0.02 \\
\hline
\end{tabular}

Table 2 The chemical composition of steel grade EK94 (wt\%).

\begin{tabular}{|c|c|c|c|c|c|c|}
\hline Fe & Ni & Cr & Co & Mo & Mn & C \\
\hline Main & 9.45 & 8.72 & 4.67 & 2.5 & 0.10 & 0.02 \\
\hline
\end{tabular}


The G8 GALILEO analyser is used to quickly and accurately determine the hydrogen content in various types of solid materials, for example, steel, iron, non-ferrous metals, alloys, aluminium, titanium and its alloys, zirconium and its alloys, powder metals, ores, ceramics, glass, cement etc.

Determination of hydrogen concentration is carried out in accordance with the method of transmission of the carrier gas through the extraction of the melt with subsequent determination of infrared or thermal conductivity.

\section{ANALYZER SPECIFICATIONS}

- $\quad$ short analysis time, automatic process, simple operation;

- temperature programmable up to $2400{ }^{\circ} \mathrm{C}$ (with sample hole cooled to $2900{ }^{\circ} \mathrm{C}$ ), non-contact optical sensor for temperature measurement and precise control;

- $\quad$ simple switching software with the simultaneous measurement of oxygen and nitrogen to determine hydrogen; the presence of an external furnace for diffusing hydrogen as additional equipment;

- $\quad$ highly stable detection system with a non-dispersive infrared detector for determining $\mathrm{CO}$ and a thermosconductometric cell for determining nitrogen and hydrogen;

- automatic zero correction for all detectors, automatic range control and selection of the optimal range for all elements;

- $\quad$ additional accurate gas calibration using a temperature-heated furnace analysis, automatic furnace cleaning and an automatic crucible feeder.

\section{ANALYSIS METHODOLOGY}

The sample is melted in an electric furnace with electrodes (pulse-heated furnaces) in a graphite crucible in an inert gas (carrier gas). The graphite crucible also has a heating element located between the two watercooled electrodes of the pulse-heated furnace, the bottom electrode is pneumatically moved down to open the furnace and up to close it. The freely programmable temperature of the electric furnace with electrodes is controlled by a non-contact optical sensor. As a result of high temperatures, oxygen, which is usually present in the sample as an oxide, reacts with an excess of carbon to produce $\mathrm{CO}$. In addition, nitrogen is released from nitrides by decomposition, and a certain amount of hydrogen is also present in the sample.

The resulting hydrogen sample gas, respectively, passes through a highly stable detection system consisting of a selective non-dispersive infrared detector (NDIR) and a thermoconductometric cell controlled by a thermal relay (TCD) to determine $\mathrm{H} 2$ along with the carrier gas. A thermal conductivity detector is used to measure hydrogen. The measuring module, controlled by a thermal relay, includes two gas supply paths. Carrier gas and sample gas pass through one path, pure carrier gas (reference gas) passes through another path. Thermal conductivity in the gas supply paths is recorded by thermistors, which are connected in a bridge configuration.

The measurement principle is based on a change in the thermal conductivity of the carrier gas caused by the sample gas compared to the flow of the comparison gas of the pure carrier gas. The signals are proportional to the concentration of the sample in the carrier gas. Nitrogen with a purity of $99.999 \%$ is used for hydrogen analysis. Measurement signals are displayed on a graphical display during analysis. The time integral of the measurement curve corresponds to the content of the corresponding element in the sample. The hydrogen concentration, respectively, is calculated taking into account the weight of the sample based on the calibration results of a certified standard sample or using an additional gas calibration device.

\section{HYDROGEN DETERMINATION REAGENTS}

Nitrogen is used as a carrier gas for measuring the hydrogen content, which, in addition to the relatively large difference in thermal conductivity compared to hydrogen, has the great advantage that any nitrogen released from the sample does not affect the measured signal at $100 \%$ pure nitrogen as carrier gas. 
In addition to replacing the helium carrier gas with nitrogen to determine the nitrogen content, the reagents are also replaced to determine the hydrogen content. In this case, the reagent located after the system of infrared radiation detectors acts as an oxidizing agent for the selective conversion of carbon monoxide (CO) to carbon dioxide (CO2), which is then adsorbed on the next molecular sieve column. After removal of carbon monoxide, the gas passes through the measuring branch of the thermoconductometric cell. Here a quantitative determination of the hydrogen released from the sample is carried out. After the measuring cell, the gas again passes through a flow meter located on the front of the analyzer to estimate the pump flow rate (usually about $0.3 \mathrm{I} / \mathrm{min}$ with $\mathrm{N} 2$ as the carrier gas).

\section{RESULTS}

To conduct the experiment on a G8 GALILEO gas analyser, 2 samples of steel of grades EK49 (03X10H8K4MF) - sample No. 1 and EK94 (03X9N9K5M3) - sample No. 2 were taken. Before starting work, the samples were weighed. The mass of the first sample was $0.615 \mathrm{~g}$, the second $-0.592 \mathrm{~g}$. The analysis time for the steels was 2 minutes 20 seconds. The analysis temperature was selected in accordance with Table 3.

Table 3 Temperature conditions for various samples.

\begin{tabular}{|c|c|c|c|}
\hline Material & Carrier gas & Temperature $\left({ }^{\circ} \mathbf{C}\right)$ & Weight $(\mathbf{g})$ \\
\hline $\mathrm{Ti}$ & $\mathrm{Ar}$ & $1700-1900$ & $0.1-0.3$ \\
\hline $\mathrm{Ti}$ & $\mathrm{N}_{2}$ & $1500-1600$ & 0.10 .3 \\
\hline $\mathrm{Zr}$ & $\mathrm{Ar}$ & $1700-1900$ & $0.1-0.3$ \\
\hline $\mathrm{Zr}$ & $\mathrm{N}_{2}$ & $1500-1600$ & $0.1-0.3$ \\
\hline Steel, cast iron & $\mathrm{N}_{2}$ & $1400-1600$ & Up to 2 \\
\hline $\mathrm{Ni}$ & $\mathrm{N}_{2}$ & $1400-1900$ & Up to 2 \\
\hline $\mathrm{Cu}$ & $\mathrm{N}_{2}$ & $1400-1600$ & Up to 2 \\
\hline $\mathrm{Ag}$ & $\mathrm{N}_{2}$ & 1300 & Up to 2 \\
\hline
\end{tabular}

In Figure 1, for the grade EK49 and in Figure 2 for the grade EK94, the hydrogen concentration was 0.0003 $\%$ each, which is acceptable values for steel and iron-based alloys. These steels can be used for work in corrosive environments and at high temperatures.

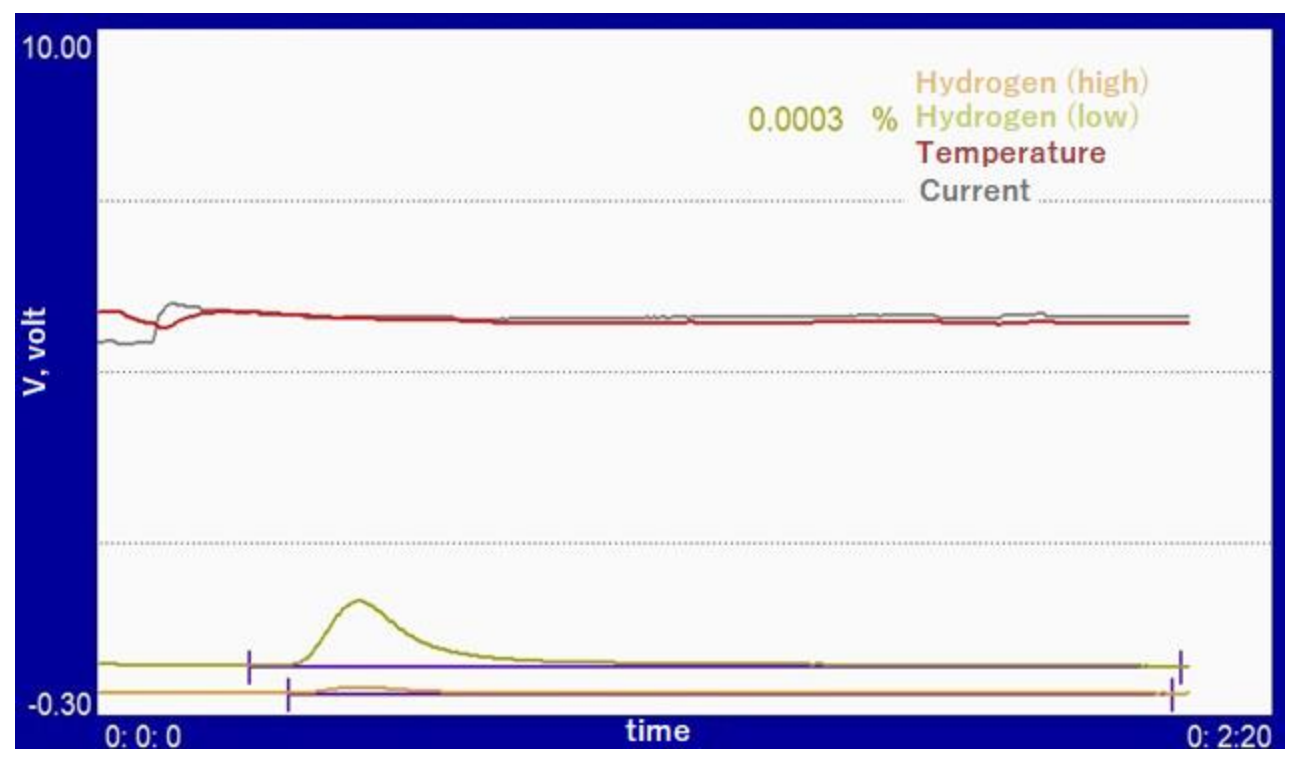

Figure 1 The percentage of hydrogen in the alloy EK49 


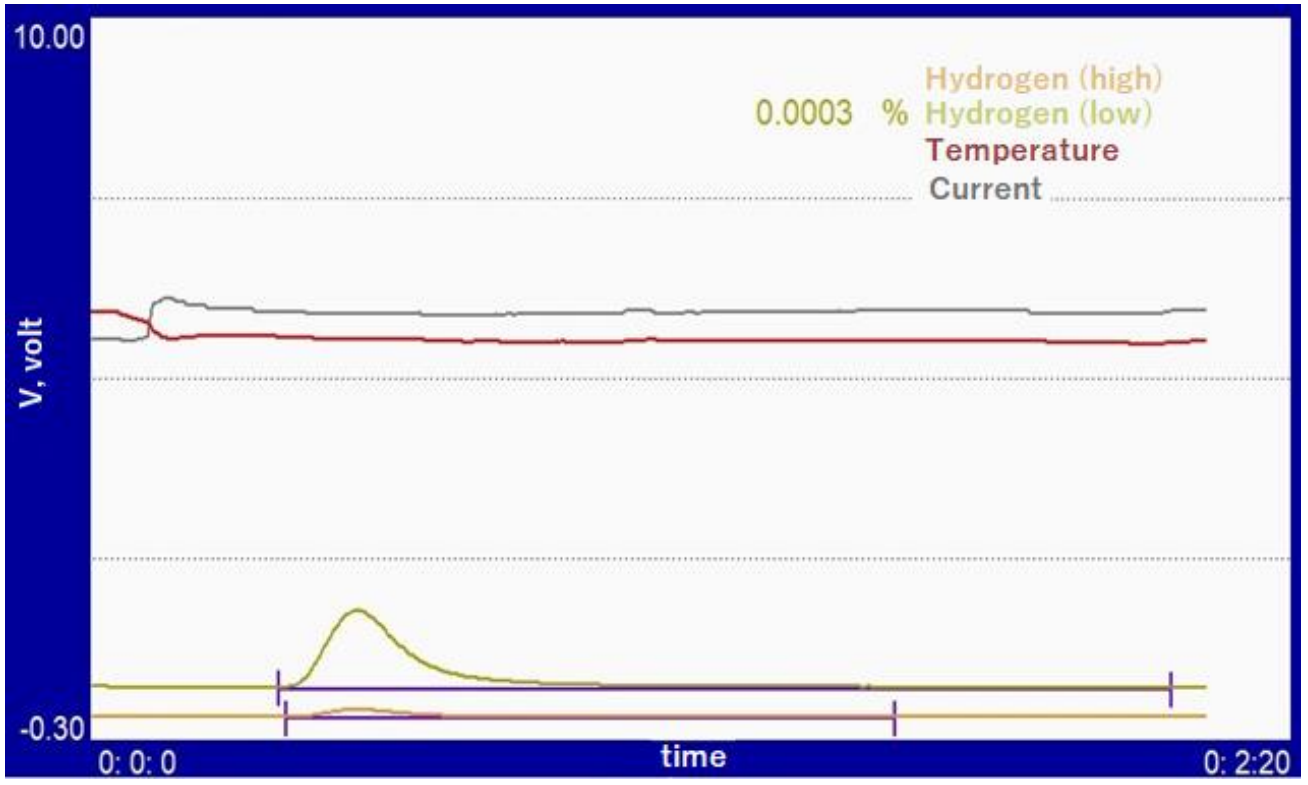

Figure 2 The percentage of hydrogen in the alloy EK94

\section{CONCLUSION}

Hydrogen embrittlement of structural alloys is a complex process. Its development is determined by a number of positions, namely: the type of hydrogen source through the mechanism of its transfer and interaction with the metal, the specifics of damage to materials. To reduce the susceptibility of a structural alloy to the damaging effects of hydrogen, it is necessary to carefully and thoroughly examine each of these items, it is especially important that such a study be carried out in relation to a specific alloy and to specific conditions of its technical application.

\section{ACKNOWLEDGEMENTS}

The work was done as part of an agreement between the MINISTRY OF EDUCATION AND SCIENCE OF THE RUSSIAN FEDERATION and Public Joint-Stock Company "KAMAZ" on the provision of subsidies from the federal budget for the implementation of a comprehensive project to create hightech production with the participation of MUCTR "№074-11-2018-008 of" June 5, 2018 and the contract between KAMAZ and the MUCTR-218-1 / 2017 for the implementation of research, development and technological works $(R \& D)$ on the topic: "Development and creation of high-tech production of urban municipal electric truck with expander and semi-autonomous vehicle control system" from 10.25.2017.

\section{REFERENCES}

[1] BRYANT, K.L., BENERJEE, S.K. Embrittlement of structural steels and alloys. Metallurgy. 1988, pp. $256-328$.

[2] KABLOV, E.N., KRIVONOGOV, G.S. The performance of high-strength corrosion-resistant steels under the influence of hydrogen. VIAM-Metals, 2002, no. 1, pp. 125-132.

[3] SKRIPCHUK, G. A. Hydrogen fragility. Young scientist. 2009, no. 11 (11). pp. 13-15.

[4] HIKEL, T., PONG, D., ROVERDER, M., NEUGEBAUER, J., RAABE, D. Hydrogen atoms in steels. Ferrous metals. 2019, vol 993, no 1. pp. 64-65.

[5] KARKHIN, V.A., TSUKANOV, V.V., NOVIKOV, E.V., KHOMICH, P.N. Analysis of hydrogen diffusion during thermal anti-flock treatment of steel. Ferrous metals. 2014, vol. 988, no. 4, pp. 68-72. 
[6] FADEEV, G. N., BOLDYREV, V. S., BOGATOV, N. A., AVERINA, Y. M. Surface treatment of metals in the field of low-frequency exposure. Non-ferrous metals. 2019. no 10. pp. 73-77.

[7] NEDASHKOVSKY, K.I., GULSHIN, A.V., AVERINA, YU.M., NAUMKINA, V.A., MENSHIKOV, V.V., BOLDYREV, V.S. Investigation of the corrosion resistance of fasteners made of high-strength steels as applied to units operating at high pressure in a marine climate. Bulletin of Moscow State Technical University. Series Engineering. 2020, vol. 130, no. 1, pp. 94-106.

[8] AVERINA, Y. M., NAUMKINA, V. A., NEDASHKOVSKY, K. I. Metallographic research into the quality of x15n27t3mr-vd steel wire (ep700-vd). Journal of Physics: Conference Series. 2019, no. 1348. pp. 1-3. 